\title{
A Narrative Study on Young Women's Job Anxiety and Counseling Experiences
}

\author{
Eun-kyung Lee ${ }^{1}$, Mi-Na Lee ${ }^{2}$ \\ ${ }^{I}$ The Doctor's Course, Department of Human Service Education, Kwangshin University, South Korea, \\ poem6805@hanmail.net \\ ${ }^{2}$ Professor, Welfare Counseling Convergence Department, Kwangshin University, South Korea, \\ lmn4780@naver.com
}

Corresponding author: $\mathrm{Mi}-\mathrm{Na}$ Lee

\begin{abstract}
The purpose of this study was to conduct story therapy on young job seekers with depression and job anxiety, and investigate on their experiences. This study took place once a week from December 2020 to March 2021, for a total of 10 sessions with 50-60 minutes per session. The research results are as follows. First, young job seekers with depression and job anxiety came to understand their fears and anxieties about job-seeking activities in story therapy and seek out job search motivations in the process of self-exploring. Second, young job seekers with depression and job anxiety could find dysfunctional beliefs that lead to depression and job anxiety during the counseling process. In addition, the participant was able to recognize her own situation by thinking about the cycle of negative emotions. In other words, through the counseling process, the participant was able to safely open and take care of herself, and gained energy for job search. The goal of this study is to contribute in providing basic data on preventing and treating psychological problems of young job seekers with the increasing unemployment rate and the experiences young people with depression and job insecurity.
\end{abstract}

Keywords: Young Job Seekers, Job Search Experience, Job Anxiety, Job Anxiety, Narrative Research

\section{Introduction}

Youth is a very unstable time when there are many changes in terms of physical, cognitive, social development, personality and emotional development, and various changes in personality and emotional development. The English word "adolescence" in Latin also means "growth", meaning a period of rapid growth. During this period, not only physical development but also social and psychological development is rapid[1].

In Korea, 15 to 29 years of age are defined as young people, and various data published by the National Statistical Office show that men in their 20s are classified as young people who enter society after being in charge of the military duty. A youth should be defined as a person who is unemployed after graduating from a university and is under the age of 20-29 and who is seeking a job with the intention to work. Youth has a common task of embodying career goals and entering the professional world with training accordingly[2]. Freud defined anxiety as a set of signals that appear as awakening when danger is detected[3], which is a concept that underlies human sentiment along with depression. Furthermore, he distinguished it as realistic anxiety, neurotic anxiety, and moral anxiety[4].

Considering the early Freudian theory based on Fehiner's theory of anxiety and Frome's argument, it

Received: May 14, 2021; $1^{\text {st }}$ Review Result: June 30, 2021; $2^{\text {nd }}$ Review Result: August 17, 2021 Accepted: September 30, 2021 
was seen that there was something in common about suppression of desire. We present the opinion that anxiety arises when individuals fail to satisfy their needs due to various factors, such as ego or social atmosphere[5]. Anxiety is a subjective and arbitrary state in which one experiences unpleasant emotions such as fear or anxiety, tension, intimidation, etc without a clear cause, and anxiety is experienced when there is no real cause of danger[6-8].

Anxiety also has social anxiety, which is feared for the process of establishing social relationships. Social anxiety disorder, also called social phobia, is a disorder that avoids and fears situations in which people interact with each other[9]. The main characteristic of the anxiety of 'anti-human fear' in social relations is that it shows a fear of making others uncomfortable[9].

Along with depression, anxiety among the young job seekers is also emerging as a problem. Research in preventive counseling suggests anxiety as well as depression among young job seekers. The study reports that risk factors for youth unemployment including low education levels, low self-esteem, social dysfunction, repeated job failure experience, depression, anxiety, frustration, and suicidal ideation should be prevented tertiary[10].

An analysis of the psychological difficulties faced by young people actually reports that young job seekers are complaining of emotional difficulties such as anxiety, contraction and depression in the job search process and want a variety of psychological interventions that can be of interest[11].

Narratives are a research method developed by Clandin and Connelly as they work on the meaning of human life. Such exploration is a method of understanding experience in cooperation between researchers and participants that occurs over time in interaction with the environment[12]. It focuses on empowering individuals' experiences as an exploration of human experience, including how to interpret and reinterpret those experiences[13][14].

Narrative exploration cannot exclude subjective and autobiographical elements because it gives insight into 'Who am I?', 'What am I becoming?'[14]. Because of the interest of research also begins with our individual's narrative experience and focuses on the construction of narrative exploration[15], the process of reviving, talking, recounting life, and reliving becomes a dynamic experience for researchers and participants, through which we looking for personal and social growth.

In this study, a qualitative case study was conducted among research participants with depression and job insecurity. Furthermore, a narrative story therapy was conducted to explore the experience and meaning of young people in depth. The goal of this study is to contribute in providing basic data on preventing and treating psychological problems of young job seekers with the increasing unemployment rate and the experiences young people with depression and job insecurity. Also, young people with depression and job insecurity prefer to reveal what they experience in story therapy and what their experience means.

Therefore, the following research questions is sought to be addressed;

1. What experience does a young job seeker with depression and job insecurity have in narrative therapy?

2. What does that experience mean?

\section{Research Methods}

\subsection{Research Participants}

The research participant is a woman in her early 20s living in G city who graduated a diploma course and is currently studying at an academy to get a job. It is a voluntary internal story that asked her for counseling due to increase depression and anxiety having counseling before quitting her job after graduation due to COVID-19. She has not experience it before, but attempting to asking for counseling again to solve her own problem now. The main appveal issue was anxiety about the future and stress 
from underlying depression and anxiety with unknown causes. Through understanding herself, the purpose of the consultation was to find the causes of depression and anxiety, identify one's aptitude, and set the direction of employment[2].

The questionnaire for each session of this study is as follows.

First, when did anxiety start?

Second, when was your bright side when you were young?

Third, do you have any difficulties in your relationships?

Fourth, what are your worries and anxieties about getting a job?

Fifth, what kind of effort did you make to live?

Sixth, what kind of person are you?

Seventh, what do you think of yourself?

Eighth, what are your strengths?

Ninth, what does your restored self look like?

Tenth, do you practice happiness?

\subsection{Process of the Research}

Clandin and Conelly[12] stated that finding the meaning of experience through narrative exploration is both a research method and a process. On the process of conducting research methods to find the meaning of these experiences, scholars flexibly present them in three, five, and seven steps[16]. However, as stated above, these steps are not distinct, and they are organically linked to each other, crossing and overlapping each other' In other words, all of the above processes are not fixed and linear, and the research is carried out cyclically and iteratively interrelated in this work too, an iterative cycle between the field and the study text has been achieved[17].

\subsection{Narrative Courses}

The researcher recorded the participant's thoughts, perceptions, and emotions through diary writing, conversations, and interviews to understand the story therapy activities experienced by alias 0 from her point of view. From December 2020 to March 2021, it took a total of 10 sessions to form field text, once a week and 50-60 minutes per session. The venue was held at the researcher's counseling center. By comfortably telling her story and changing her perspective, she improved her understanding of herself and found her own cause of depression and anxiety. As sharing feelings as watching myself being reilluminated, it could have a positive view of myself by renewing my perception of myself.

\subsubsection{Presence in the Field (Enter the story)}

Narrative exploration first constructs narratives about the researcher's own experience at the beginning, which can form a research puzzle, set criteria for selection of study participants, and help researchers' exploration to have personal, practical and social legitimacy[16]. This is because it aids in the collection and interpretation of data that will be carried out of the future as an exploration of the researcher himself related to the research topic before entering the site[15].

The researcher majored in a master's degree in counseling, completed a doctorate in education psychology, and is currently working at the $\mathrm{H}$ counseling center, and has been meeting various countsellers at the counseling website for more than 10 years.

Remembering the difficulty of failing to go to college in 20 s age and finding a job in a vague state when listening to their concerns while consulting with college students and young people, there was anxiety about finding a job along with the internal part of the person. It occurred to me that young people 
would be able to deal more actively with the problem of finding a job if they explored and interpreted their problems, understood their lives, and clarified their career paths. The researcher, like the participants in the study, felt anxious in a vague state, and shared their anxiety, talked with them, and went to in the scene where they were in consultation.

\subsubsection{Move from Site to Field Text (Exist in story space)}

This step is for the researchers to enter the field, collect data, and think about writing field text. First of all, in the field, researchers are concerned about how deeply they will participate in the study web site[2]. Researchers should be fully immersed in the field and 'fall in love' with the participants[14] on the other hand, they should be able to take a step back and see the stories of the researchers and participants within the larger context of their lives while when writing and reading the field text[2]. The reason for using field text is that data which is undiscovered or found, but created by researchers and participants to demonstrate aspects of experience in the field[14]. The data will be made by researchers and research participants together. When collecting field text in the narrative exploration, researchers should make an effort to record field text as habitually, accurately and abundantly within a 'threedimensional narrative exploration point' called 'sociality', 'timeliness', and 'place'[14]. Therefore, it is necessary to question and record not only the participants' verbal representations but also their nonverbal representations such as their feelings, thoughts and behaviors[16].

\subsubsection{Organizing Research Text}

Narrative explorers recommend several methods for the role and position of researchers in the threedimensional narrative exploration space at the time and social level in writing research texts. Summarizing their recommended method, it is recommended to imagine their field text and research puzzles through reading books related to reading narratives, find meaningful metaphors that can express their research topics, read extensively, and continue to study and experiment with the narrative process. In addition, the research text composed of chapters is repeatedly read simultaneously, comparing and contrasting one chapter with another, pursuing and modifying overall narrative unity with a sense of 'aesthetic completeness'[16].

\subsubsection{Ethical Aspects of Research Participants}

In order to secure the reliability of the study, the consultation process was conducted weekly with expert feedback, and ethical aspects of the research participants were agreed to write in the paper and the consultation was conducted. It is permitted not to be used for profit other than papers and journals.

\section{Actual Narrative}

\subsection{The Story of a Client}

The first meeting with the counsellor was a young woman in her 20s who graduated from a university and worked part-time after graduation, but lost her job due to the COVID-19 pandemic. According to the subject, "My grandmother raised me until I was seven years old because my parents worked together, and I lived with my parents after that, and I was very sad at that time." It is believed that separation instability occurred at this time. It is said that she did not show much affection to the person in charge because her parents were double-income and blunt. Both parents and mother-in-law were said to be anxious and scared because adults often fought. In a situation where the family was uncomfortable, she relied on her school friends a lot. "I relied on my friends because my family was not comfortable, but 
the incident in the first grade of middle school raised anxiety about interpersonal relationships. In college, my parents only paid for the tuition and the rest of the tuition was covered by my part-time job." She is said to have received scholarships by studying hard because she has a high level of anxiety and a desire for self-development. "I asked for a consultation because I felt anxious and lethargic while taking a break from work."

\subsubsection{First Story (The beginning of anxiety)}

When I first saw her, she seemed to have no makeup, no strength, and very intimidated. I asked about the counseling because it might be a little unfamiliar because it was our first meeting. And I asked how you have been these days. When asked the hardest thing, she said she was very lethargic and anxious. I felt a lot of depression and anxiety subjectively, so I tested Aaron Beck's depression and anxiety in advance, and the results showed that she was experiencing considerable depression and anxiety due to depression at 25 and anxiety at 43 .

According to her, "I think it's been a long time since I was asked when I felt depressed and anxious, but I think I quit my job and become more lethargic and anxious these days. My parents often argued at home about where I thought anxiety started. Maybe it was because of the money. Even now, if I ask them to buy me something to eat at home, they scold me saying I can't because I don't have enough money. My mom always says, "Money, money, money." But I liked going to school and spending time at school. Elementary school was fun. When I was in the 1st grade of middle school, I had a disagreement with my best friend while talking about my favorite celebrity. I thought I'd stop, but he moved away from the friends I was hanging out with at the time and became a loner alone. I think I feel a lot of anxiety when I meet people with Iruo. I felt more difficulties in relationships with people than at work." I gave her a depression and anxiety scores from the pre-test. She feels subjective. I think both depression and anxiety are about 9 out of 10 . But 5 points would be fine.

The anxiety of the counsellor is old, and the depression and old anxiety while resting from work are added to the current state of lethargy. It was not comfortable at home because there were many arguments from parents and it was fun to go to school. However, in the first year of middle school, a minor quarrel with a friend caused her to turn his back on other friends. Since then, the counsellor has become depressed and anxious about relationships with people. It was a shocking experience for a counsellor who had a lot of psychological dependence on her friends because she could not build a warm relationship at home. Since middle school, she has been passive in friendship and always agrees with other people's words. It was also said that it was too hard to care about relationships with people rather than work at work. "Then, I closed the door due to work conditions, and I took a rest, and the old depression and anxiety got worse again, so I visited the counseling room." Early last year, she took medicine in psychiatry, but stopped because she could not find the cause of her problem. "Are you sure my problems will be "solved?" She came with half a doubt. Nevertheless, visiting the counseling room would have been possible because she had the will to solve her problem. Even if the depression and anxiety she felt were too low, she didn't think high of expectations because she was worried that she would become conceited. I thought I was the type to reflect on myself a lot.

\subsubsection{Second Story (Finding Brightness as a Child)}

The counsellor still looked powerless and lethargic. However, it was thought that there was a possibility of change because there was a willingness to solve one's problem through counseling. Last time, she identified the state and cause of anxiety and depression she feels now. "I asked a question to further understand my mind."

"I haven't been able to relax in a while. I'm always nervous and my head is always complicated. And I'm nervous. I was wondering if I missed anything. It's hard to think that you have to be perfect and 
obsessive. I remember when I was in the first grade of elementary school, but my father and mother fought a lot over financial issues. I'm fine with my dad, but my mom scolded me a lot when I was 6-7. I hit him and threw things. At first, I thought, "What did I do wrong?" I blamed him, and I thought it was a relief that he didn't throw it away when he was financially struggling. These days, I feel lethargic, unable to concentrate, abandoned, and at a loss. I care about interpersonal relationships. What if I do something wrong? My personality was cheerful and optimistic when I was young. So I was happy outside and didn't want to go home. Then, I started to shrink as I went to middle school and high school."

"When I said this, my eyes sparkled. Then I said I would do it even though I don't remember." For the first time since the consultation began, I saw the person bring her body forward and her eyes sparkle. Since the incident in middle school, the counsellor, who has been cheating on herself and fitting in with people, seemed to expect to rediscover her power and regain her appearance. It can be seen that the work with a friend has become a big wound for the counsellor who relied on her friends because the family was not comfortable. But it was a session when I learned that just discovering that I had been a powerful person before that would give me strength.

\subsubsection{Third Story (Difficulties in relationships, desire to be recognized)}

"The person in charge is currently resting for about a month and a half due to the closure of the store in the aftermath of COVID-19 while working. I couldn't afford to look back on my mind because I had been living hard, but I ended up facing my long hidden heart in a resting situation. In doing so, the wounds of my school days came back to me and I was in a situation where I had to solve my inner problems with anxiety about the future".

The past week has been more comfortable than I thought. But I'm scared when I lose my emotions because of the ups and downs. I don't know what to do in that case. I think it's because it's a habit to suppress emotions. It's good to use the emotions that come to mind to express emotions, or to express them through walking or moving. When I'm alone, I watch movies on Netflix. I used to watch calm movies, but I watch funny movies these days. When I was in middle and high school, I got social phobia about friendships and interpersonal relationships. I get discouraged in relationships with people, so I always adjust myself to others. After that, I feel skeptical. I hung out with my friends from the same group when I didn't play because I had a disagreement with my friend in middle school. But he attacked me when we went on a school trip because he said something to other children. And then he beat himself up. When I was in high school, I had a chance to make up after a small fight, but I couldn't because of my middle school memory. It was really hard and painful to have a friend in middle school who dragged other friends into a fight. I feel like my initiative is collapsing because of that. I want to start over by practicing self-asserting when I'm with safe people."

You can see that the counsellor has been holding back her feelings by giving up on claiming herself and fitting herself to others. "Just because my mother beat me and scolded me when I was young, I assumed that my mother's role was also in the fear of people and asked questions about my mother. (I asked in front of the doll to replace my mother) I'm scared of how my mother feels. What I wanted to hear from my mother the most is to acknowledge me. It would be nice if my mother recognizes it, but there's a way to acknowledge yourself when you can't. You respect and acknowledge yourself. I'll write my own feelings in my diary and find the strength in myself by giving encouragement to my words when I'm alone."

Interpersonal difficulties appear to have been experienced due to injuries in relationships at home and at school. It can be seen that the person in the family wanted to rely on the mind outside because there was no one to rely on. "Even now, my mother does not comfort me affectionately. They say that they are scolding them more because they are staying at home these days. So I taught myself how to comfort and encourage myself. He recommended that you write down what you did every day in your diary and 
practice praising yourself for doing well every day." It must have been frustrating and difficult for a counsellor who had a strong desire for recognition and a strong self-assertion to suppress her opinions and adjust them to people. I encouraged myself to practice this, hoping that I would have a positive mind through self-encouragement.

\subsubsection{The Fourth Story (Unemployment and anxiety).}

This session mainly talked about getting a job. Since the counsellor just graduated from college last year and quit her job due to her job situation, it is a big concern in the counsellor's age group because of the anxiety about employment and the future. "After graduating from Food and Nutrition, I am interested in cooking. I want to learn confectionery baking, but I have a lot of thoughts about learning it by myself. If you close your eyes in the meantime, you'll have a lot of course. I wonder if what I want to learn is a waste of time. I'm trying to learn how to cook, but I'm worried that I don't hire women very well. I don't know if it's because I'm old or because of lethargy. So I'm thinking about doing a less difficult confectionery and baking. I have a Korean food license, so I put in my resume, but I can't get hired well. I'm having a hard time getting a job. There are a lot of older sisters who live hard around me. I have an older sister who studies more by getting a license and transferring to a university. So it compares and gives me an inferiority complex. My parents don't apply for a license study. He didn't pay me anything but college tuition. When I was in college, I got a scholarship and worked part-time, so I went to school by solving pocket money and tuition. I've been working part-time until now. Last year, I took a break from work due to COVID-19, and it's been a month and a half since I took a break. I have a lot of thoughts as I spend more time alone. I stood alone after college. Encouragement somehow feels like self-justification." For economic reasons, the counsellor went to school alone, earning college tuition and receiving scholarships. "While attending school, I went to academy on my own and lived alone enough to get a certificate of Korean cuisine chef. It's been running without a break. Currently, as I rest in the aftermath of COVID-19, I am having a harder time with worries about getting a job and anxiety that has been dormant since I was young." It is a situation where young people in their 20 s are suffering from anxiety about employment and anxiety that the counsellor had.

\subsubsection{The Fifth Story (A struggle to survive)}

Last session, I shared how hard the person in charge has lived alone. She has been preparing to get a job by paying for her tuition and academy expenses due to economic conditions. Nevertheless, the cooking industry has a wall for women, so they are trying to learn confectionery and baking, which are less difficult and relatively easy to get a job, but they shared their concerns about whether it is right.

"I registered to learn how to cook yesterday. Monday and Tuesday education starts after Lunar New Year's Day. And I decided to go to a part-time job on this Thursday, Friday, and Saturday. I always get emotional ups and downs. It's a little down right now. I didn't know after fighting with my friend when I was in 9th grade, but I got depressed when I was in 9th grade. After that, when I met people, I went overboard and pretended to be happy. For a long time, people were like, "What do you like so much every day? You don't look worried," he said. I don't trust people after that now. My friends say I'm too suspicious. I want to tell you that I have endured what I wanted to say to myself. I feel like I'm struggling to survive."

It was a session where I felt proud and proud of the fact that the counsellor made a decision on what she had hesitated to do with her will for life and began learning. It was a session where she clapped loudly for the determination and courage that she took a step closer to her future despite her worries. I can feel the sorrow of the counsellor's heart when she said she was struggling to live. Now I want to feel more relaxed. 


\subsubsection{The Sixth Story (What kind of person am I?))}

"After feeling lethargic, depressed, and anxious for about a month and a half, I decided to start working part-time again and learning to get a job, and I was very curious about how you were doing for a week. As a counsellor, it would have been a great boost. I wanted to give such a counsellor more strength. The depression seemed to have decreased a lot, so the BDI test again confirmed that it was 20 points, down 5 points from the start of the consultation.

I started my part-time job, but I was worried about whether I could do well or not when I was working, but I was able to do it comfortably this time. I think I'm more relaxed about myself now. I think it was helpful to keep encouraging me. When asked about depression and anxiety, I said 9 out of 10 in the first session. I think it's about 7 points. That's about 2 points lower. I think I got more depressed and anxious because I thought a lot during the break. When you feel mood swings, your interest disappears. I feel bored. I think there are a lot of distractions, too. I like to do it with my hands. Things you cut with scissors. I don't like the feeling of falling behind. It's boring and hard to find meaning in my spare time. Last year, I was busy attending school, part-time job, and academy, but I was depressed. I was beaten up by people and showed myself not who I really am. Actually, it wasn't okay, but they all said it was okay and matched it to people. I think people might think I'm weird. There may be anxiety that says, "What should I do if my true self is known to people someday?" I want to be confident about myself now.

I can't say it easily because I'm asked to say the advantages of myself. I don't think I know who I really am because I've been denying myself for a long time because of what happened in middle school." Originally, the counsellor was a self-asserting person, but after breaking up with a friend in pain with such self-assertion, she formed a relationship that suited herself to people without any self-assertion. In the meantime, she seems to have experienced psychological anxiety and depression due to her alienation. "I think it must have been very heartbreaking due to severe self-denial and self-distortion. Now, I consulted with the hope that I could find my true self and express it to people proudly people."

\subsubsection{Seventh Story (Perception of who I really am)}

"Last year, when I took a break from work, I was worried that I would suddenly get tired of doing many things while being proud of myself, as I went to academies, honed my skills, and even worked part-time. That's how I started the consultation.

These days, I bake on Mondays and Tuesdays and learn baking on Wednesdays and Fridays. While we're at it, we decided to do everything. But I'm also thinking about getting a job. I have a part-time job on Thursday, Friday and Saturday. I'm worried that my physical strength will deteriorate due to my busy life, but I'm okay so far. But I'm a little worried that I might get emotional ups and downs. I think I've been anxious since I had an argument with my friend when I was in 7th grade. I grew up in my grandmother's house when I was young. My grandmother raised me until I was 6 years old because my parents worked together. At that time, I was told that I was outgoing and smart. My maternal grandmother and maternal grandfather fought a lot at that time. My parents raised me after I was 6 years old, and my parents often fought." I think there were a lot of unstable situations. But I think she was originally a bright and self-asserting person. "It's amazing to see myself like this. It's about talking confidently and working hard and living wherever you want. Now I want to make up with myself and find my original self. I think you've been neglecting me. Now I want to find myself again."

While attending an academy, the counselor said there was anxiety about getting a job. "I was worried that it would be better to jump into the job market instead of learning something." It was also a session where she learned the cause of her anxiety. "My parents worked together, so I stayed at my maternal grandmother's house until I was six years old, and suddenly I lived with my biological parents, which must have caused separation anxiety." It is also speculated that the young counsellor felt a lot of anxiety 
as she often saw adults fighting at her grandmother's house or at her parents' house. The anxiety of the counsellor is an old feeling that began in childhood.

\subsubsection{Episode 8 (I wasn't a weak person).}

"Last week, Aaron Beck's Anxiety Test (BAI) identified my anxiety. The depression test (BDI) test, which was conducted again in the sixth session, showed that the depression was about 20 degrees, but the anxiety was still quite high (38) and talked about the feelings of anxiety again.

I'm glad I don't think much because I'm busy these days. The anxiety test (Aron Beck) showed a high score of 38 points. The cause of anxiety may have occurred more in the process of moving into a paternal home while living in a grandmother's house as a child. I remember living at my grandmother's house until I was 6 years old and crying a lot the day I went into my parents' house. Breaking up with my grandmother, hurting my friend who gave me my heart, and after a quarrel with my friend in the $1 \mathrm{st}$ grade of middle school, I think I got to trust people wrong. I thought I was having a hard time because I was weak before. But now that I hear it, I think I wasn't weak. I thought I was in a situation where I had no choice but to. I'd like to tell you that I've been working hard. It is necessary to practice separating depression and anxiety from current emotions. I'm afraid I'll get conceited if I compliment myself too much. I've had a hard time so far and I've been working hard, so I'd like to compliment myself a lot."

The anxiety of the counsellor is an old feeling that began in childhood. When I saw her like that, I asked her how she felt, and she said she felt comfortable knowing that she was not only weak. She knew the cause of anxiety and found that it was an old habit of mind. "It was the first time that I expressed myself to myself that I had struggled. It was a session where self-acceptance and self-care began due to understanding of oneself. I felt proud to see such a self-love of the person in charge."

\subsubsection{The Ninth Story (I found myself again)}

Last session was the session in which the identification of the cause of the anxiety of the counsellor and self-care of the counsellor began. Self-acceptance began as the counsellor became more aware of herself. Such a change allows us to expect that we will be able to live a life where we encourage and support ourselves more in the future. Since the last time, the BAI has been re-examined.

Now it's good to practice encouraging herself even with some free time. Also, it is good to have a hobby to make by hand. In the last examination, the cause of the anxiety may have occurred while living in the grandmother's house as a child and moving into her family's house. "It must have been painful to fight with my friend in middle school. I got 20 points today. It's decreased a lot, but there's still anxiety. Another is anxiety about the future. I'm worried if this is the right way. I'm also interested in nail and pottery. I think I usually like to do it with my hands. How do you feel when you cook? I'm curious about the reaction of people who ate."

The researchers would like to give the counselloer 8 out of ten points for satisfaction with herself. "I only took the prescription for 5 months, but I couldn't figure out the cause of my problem. I didn't go because it didn't seem to work even if I kept taking the medicine. But now that I know the cause of my anxiety and depression, I feel more confident than before. I was indecisive, but now I've decided more firmly. I think it's because I learned the reasons for my old anxiety and depression. At first, I thought I could consult, but now I'm happy to know myself. I'm not a weak person, but I have strength, but I found out that I was weakened by various situations. I feel like I've done well on my own."

I could see that the counsellor had a wider understanding and acceptance of herself. As she became more confident in herself, she was able to make firm decisions. She found out that she was originally powerful and able to express herself, and now she can express herself. Satisfaction with oneself has also increased, indicating that the counsellor has become more likely to like herself. Since the self-perception of the counselor has changed positively and the self has become healthier, the counseling cycle has been 
set for about two weeks after consulting with the counselor, and one or two more consultations and closing.

\subsubsection{Tenth Story (Happiness exercise)}

The consultation was scheduled to take place two weeks later, but due to the situation of the consultant, it was postponed for another week and we met three weeks later. For the first time in three weeks, I was very curious about how the person felt. I wondered if she had been comforting herself well. Again, BDI and BAI tests were conducted, with depression (BDI) scores down to 12, and anxiety tests (BAI) down to 15 .

The depression and anxiety scores seem to have decreased significantly, so it seems to have stabilized to some extent. "I feel comfortable with myself for the past three weeks. I've been so busy for the past three weeks. There are times when I feel a little down in the evening, but other than that, it was okay. There are times when I get in trouble because I'm not used to my recent part-time job. That's when I get a little down. I want to have a career in cooking and become a cooking technician. These days, I feel more comfortable than before consulting. Because I found out why I had a hard time. I hope this mind is maintained, but I'm afraid I won't be able to. Efforts may be needed to positively change the old habit of anxiety. That could be a daily word of encouragement. I used to say encouraging words every week, but after a while, it became less. I need to practice again. And I sometimes feel anxious that people will like me and not like me. I think I need to practice encouraging myself more. Now, the subjective depression and anxiety are about 3 4 out of 10. Actually, I don't know what happiness is. I guess I've gotten too used to my feelings. Thank you, teacher. They let me know who I am. If it weren't for this consultation, you would have been blaming yourself for being weak. I want to get a job next time and become a great cook and see you again. I think I can live happily ever after."

Even during the period of not consulting, the counselor confirmed that she had been working hard. "However, I was worried that my current state of loving myself and being comfortable would not last. It may be because of the old feeling of unease in the inner circle." Anxiety has become a habit due to childhood wounds. Changing unconscious habits requires some new habits for a long time. I encouraged the counsellor to practice encouraging and cheering for her every day for a new habit. I desperately hope that the counsellor will always practice encouraging and cheering for herself so that she can maintain her comfortable and stable mind as she is now. Now that she has recognized her strength and knows how to encourage herself, she will live her life passionately. I support her who loves herself more and lives happily ever after.

\subsection{After the Consultation}

After the counsellor found out the causes of her anxiety and depression and found the strength she had originally through her childhood memories, she confirmed that her satisfaction with her increased and depression and anxiety decreased. The counsellor was originally self-assertive, decisive and cheerful, but she suffered in the process of changing her parenting from her grandparents' upbringing to her parents' quarrels, which seems to have increased anxiety. "I relied on friendship due to family inconvenience, but depression and anxiety increased as I even experienced interpersonal difficulties in the process of moving away from other friends due to an argument with my friend in the first year of middle school." She seems to be firmly responsible for herself through her efforts and participation enough to cover university tuition on her own. She is a person who works hard, has the ability, and can get as much results as she tried, as she received scholarships while working part-time on weekends while attending university. Nevertheless, she lost confidence and struggled with old depression and anxiety. Through efforts to find the cause of her depression and anxiety and find her strength, she found her 
career path, learned and learned hard, and recovered her self-esteem a lot. Now She will make a strong move toward her life. I'm rooting for that.

\subsection{Meaning of Story Therapy Experience}

A new discovery of oneself, soar again.

In the meantime, she was weak because she blamed herself for feeling anxious and depressed Through counseling, she learned that the problem of her mind was caused by a long period of wounds, such as the environment in which her childhood caregiver changes (from grandmother to parents) and the experience of being bullied by her friends after friction with her middle school friends. After figuring out the cause of the problem, she discovered that she was a man of integrity until elementary school by finding her true self. Also, learning about ownself who went to university by own and lived hard by going to academy with scholarship. Through this experience, she realized that she was not a weak person, but that she has been suffered from the previous unstable experience overlapped with the current unstable situation. Since then, the student has become passionate about life again, such as attending private institutes and working part-time to improve her skills in her field. The counsellor flew back up to achieve her life.

\section{Conclusion}

This study is an individual case study that explores and analyzes the process of anxiety reduction, confidence in career paths, and positive changes in women in their 20 s, who experience anxiety through story therapy.

The subject of this study is a young unemployed woman in her mid-20s living in G City, who developed depression, lethargy, and anxiety as she became unemployed due to COVID-19, and asked for counseling while experiencing shrinking relationships with others. A total of 11 sessions were held from January 2021 to April 2021, 60 minutes per session. The psychological changes and effects of the counsellor through story therapy are as follows. Throughout the course of narrative therapy, we listened to and analyzed the story of the patient's life, and examined Aaron Beck's depression (BDI), anxiety (BAI), and self-subjective measures to confirm the decrease in the patient's depression and anxiety. We also focused on the subjective feelings of the audience and analyzed changes in her acceptance and positive perception of herself. On the subjective 10-point scale, the depression and anxiety that the counsellor felt subjectively during the initial counseling session were nine points. When asked about subjective depression and anxiety scores in the 10th session of the closing counseling session, it was said that it was about three to four points. In the first session, it was confirmed that the subjective goal of depression and anxiety reduction was to be lowered to five points. Aaron Beck's anxiety test (BAI) scored 43 points in the first and 38 points in the eighth sessions, but decreased to 15 points in the 10th (closing session). The anxiety seems to have decreased because the counsellor was relieved to know the cause of his anxiety. She said that she realized that she was powerful and that she could make firm decisions, not her old indecision. It was able to be confirmed that the passion for her life was revived enough to solve the expenses by attending related academies and part-time jobs to get back to work, having many negative thoughts and no desire and passion for daily life due to lethargy, depression, and anxiety.

Therefore, based on the results of the study, it was found that young job seekers who experience anxiety have an opportunity in their perception of themselves through the process of understanding their fears and exploring themselves during the story therapy process. 


\section{Reference}

[1] H. S. Jang, Youth Psychology, Seoul: Hakjisa, (2003)

[2] M. S. Jeon, A Narrative Inquiry About The Experience Of The Art Therapy For A Female Job Seeker in Twenties, Yeungnam University Graduate School, Master's thesis, (2015)

[3] S. Freud, Inhibiyions, symptoms and anxiety, (The Standard edition), W.W. Noyon \& Company, (1990)

[4] M. H. Lee, A study on effect of spiritual well-being on the relationship between separation-individualization and anxiety among Christian emerging adulthood, Soongsil University graduate school, Master's thesis, (2019)

[5] S. H. Kim, A study on pastoral care to heal anxious Korean young people, Ewha Womans University Graduate School, Master's Thesis, (2017)

[6] C. D. Spielberger, Anxiety: Current Trends in Theory and Research:1, New York: Academic Press, (1972), https://doi.org/10.1016/B978-0-12-657401-2.50008-3

[7] Soren Kierkegaard, The concept of anxiety (C. G Lim., trans), Seoul: Dasan Writing Room, (2007)

[8] D. E. Jeong, A Qualitative Case Study on Art Therapy for young job seekers with depression and job anxiety, Ewha Womans University Graduate School, Master's Thesis, (2019)

[9] E. J. Kim, A phenomenological study on the psychological counseling for the youth with social anxiety, Daejeon University Graduate School, Doctoral Dissertation, (2017)

[10] G. J. Kim., J. Y. Lee, A. R. Lee, Research Trends and Intervention Plans on Youth Unemployment in Korea from the Preventive Counseling Perspective, Korea Journal of Counseling, (2013), Vol.14, No.1, pp.115-141, DOI : 10.15703/kjc.14.1.201302.115

[11] C. R. Yoon, Psychological difficulties and support needs of job applicants, Myongi University Graduate School of Education, Master's Thesis, (2017)

[12] D. J. Clandinin, F. M. Connelly, Narrative Inquiry: Experience and Story in Qualitative Research, San Francisco: Joeesy-Bass Publishers, (2000)

[13] C. Y. Oh, A narrative exploration of the sense of vocation and identity seen through the life of a pastor's wife, Korea Bible University, Doctoral Dissertation, (2020)

[14] G. S. Yeom, Understanding the world of young children through narratives: Focusing on the study of the transition experience from kindergarten to the first grade of elementary school, The Journal of Anthropology of Education, (1999), Vol.2, No.3, pp.57-82, UCI: I410-ECN-0102-2015-300-000592583

[15] Y. S. Hong, Knowing on Narrative Inquiry, Journal of Narrative and Educational Research, (2015), Vol.3, No.1, pp.521, DOI : 10.25051/jner.2015.3.1.001

[16] S. J. Lim, A narrative exploration of the life of a middle-aged woman who experienced childhood parental abuse, Hanse University Graduate School, Doctoral Dissertation, (2020)

[17] Y. C. Kim, S. W. Jung, An Inquiry on Writing Techniques for Phenomenological Research, Journal of Education \& Culture, (2014), Vol.20, No.3, pp.5-42, DOI : 10.24159/joec.2014.20.3.5 